\title{
Toxicity Effects of Amlodipine on the Testis Histology in Adult Wistar Rats
}

\author{
Adefule Adebayo ${ }^{1}$, Adesanya Olamide ${ }^{1}$, Akpan Helen ${ }^{1}$, Huthman Ibrahim Oluwaseun ${ }^{1, *}$, \\ Soyebo Olusegun ${ }^{1}$, Huthman Adebukola Selimot ${ }^{2}$
}

1Department of Anatomy, Faculty of Basic Medical Sciences, Olabisi Onabanjo Univeristy, Ikenne Campus, Ogun State, Nigeria 2Department of Chemistry, Federal Institute Of Industrial Research Oshodi (FIIRO), Lagos, Nigeria

\begin{abstract}
Amlodipine is one of the calcium channel blocker class of antihypertensives used in the treatment of hypertension. This study was carried out to appraise the toxicity effects of Amlodipine on the testis histology in Adult Wistar rats based on the fact that amilodipine is usually consumed by the elderly who have a slow metabolic rate hence leading to accumulation of the drug in their system causing toxicity. The rats were divided into 3 groups: one group one was given normal saline while group 2 and 3 were administered with $0.052 \mathrm{mg} / \mathrm{g} / \mathrm{BW}$ and $0.104 \mathrm{mg} / \mathrm{g} / \mathrm{BW}$ of amlodipine respectively for 5 weeks. Our preliminary observations showed that administration of Amlodipine lead to an abnormal morphology of the testis in that, it had a deleterious effect on the seminiferous tubules in a dose related fashion.By these preliminary observations, alteration in the testis histology may have implication for infertility in man.
\end{abstract}

Keywords Amlodipine, Hypertension, Testis, Seminiferous tubules, Infertility

\section{Introduction}

Amlodipine (as besylate, mesylate or maleate) is a longacting calcium channel blocker (dihydropyridine class) used as an anti-hypertensive and in the treatment of angina[1]. Like other calcium channel blockers, amlodipine acts by relaxing the smooth muscle in the arterial wall, decreasing peripheral resistance and hence reducing blood pressure; in angina it increases blood flow to the heart muscle. Amlodipine does also act as Functional Inhibitor of Acid Sphingomyelinase(FIASMA)[2]

Almost all healthy male vertebrates have two testes. They are typically of similar size, although in sharks, that on the right side is usually larger, and in many bird and mammal species, the left may be the larger. The primitive jawless fish have only a single testis, located in the midline of the body, although even this forms from the fusion of paired structures in the embryo[3]. In mammals, the testes are often contained within an extension of the abdomen called the scrotum. In mammals with external testes it is most common for one testicle to hang lower than the other. While the size of the testicle varies, it is estimated that $21.9 \%$ of men have their higher testicle being their left, while $27.3 \%$ of men have reported to have equally positioned testicles. This is due to differences in the vascular anatomical

* Corresponding author:

huthmanseun@yahoo.com (Huthman Ibrahim Oluwaseun)

Published online at http://journal.sapub.org/ajmms

Copyright (C) 2012 Scientific \& Academic Publishing. All Rights Reserved structure on the right and left sides. In healthy European adult human males, average testicular volume is $18 \mathrm{~cm}^{3}$ per testis, with normal size ranging from $12 \mathrm{~cm}^{3}$ to $30 \mathrm{~cm}^{3}[4]$. The average testicle size after puberty measures up to around 2 inches long, 0.8 inches in breadth, and 1.2 inches in height $(5 \times 2 \times 3 \mathrm{~cm})$. Testis is surrounded by a thick capsule of dense connective tissue tunica abuginea thickened on the posterior surface to form mediastinum testes from which a fibrous septa penetrate to divide it into about 250 pyramidal compartments called seminiferous tubules[5]. Seminiferous tubules produce male reproductive cells spermatozoa at a daily rate of about $20,000,000$ while adult interstitial cells also known as leydig cells secrete testicular androgens. Each testes has about 250-1000 seminiferous tubules that measure about $150-250 \mathrm{uM}$ in diameter and $30-70 \mathrm{~cm}$ in length. The combined length of the tubule of one testes is about $250 \mathrm{~m}$ [5]. The tubules are convoluted and have the form of loops at whose ends; the lumen narrows and continues in short segment known as straight tubules or tubuli recti that connect the seminiferous tubules to an anastomosing labyrinth of epithelium-lined channels, the rete testis connected by 10-20 ducti efferent to the cephalic portion of epididymis. The seminiferous tubules are lined with a complex stratified epithelium called germinal or seminiferous epithelium which consists of two types of cells the sertoli or supporting cells and cells that constitute the spermatogenic lineage whose cells are stacked in 4-8 layers whose function is to produce spermatozoa and the outer wall is surrounded by a well defined basal lamina and a fibrous connecting tissue consisting of several layers of fibroblast[6]. 
Hypertension (HTN) or high blood pressure is a chronic medical condition in which the blood pressure in the arteries is elevated. It is the opposite of hypotension and is classified as either primary (essential) or secondary. About $90-95 \%$ of cases are termed "primary hypertension", which refers to high blood pressure for which no medical cause can be found[7]. The remaining $5-10 \%$ of cases (Secondary hypertension) is caused by other conditions that affect the kidneys, arteries, heart, or endocrine system.. Hypertension is the most preventable risk factor for premature deaths world wide[8] It increases the risk of ischemic heart disease[9], stroke[10] and peripheral vascular disease[11] other complications include retinopathy, hypertensive nephropathy.[12]Hypertension is also the major treatable risk factor associated with silent stroke[13]. Several factors influence blood pressure, life style factors that lower blood pressure include: reduced dietary or salt intake[14], increased consumption of fruits and low fat product, exercise[15], weight loss and low alcohol intake[16]. The role of other factors such as stress, caffeine consumption[17] and vitamin D deficiency[18] are less clear cut. Hypertensive patients in the year 2000 were estimated to be nearly one billion people or $26 \%$ of the adult population have hypertension worldwide.[19] It was common in both developed (333 million) and undeveloped (639 million) countries.[19]However rates vary markedly in different regions with rates as low as $3.4 \%$ (men) and $6.8 \%$ (women) in rural India and as high as $68.9 \%$ (men) and $72.5 \%$ (women) in Poland.[20]

In 1995 it is estimated that 43 million people in the United States had hypertension or were taking antihypertensive medication, almost $24 \%$ of the adult population.[21] The prevalence of hypertension in the United States is increasing and reached $29 \%$ in 2004.[22, 23] It is more common in blacks and less in whites and Mexican Americans, rates increase with age, and is greater in the south-eastern United States. Hypertension is more prevalent in men (though menopause tends decrease this difference) and those of low socioeconomic status[7] Hypertension in neonates is rare, occurring in around 0.2 to $3 \%$ in neonates, hence blood pressure is not measure routinely in healthy new born[24] and also a lot of treatments have come up for hypertension. An Angiotensin Converting Enzyme (ACE) inhibitor have recently been confirmed in a prospective observational multicentre trial of 1250 hypertensive patients[25]

Considering the amount of people that will be using amlodipine as a hypertensive and the fact that its mostly the elderly, who have a slower rate of metabolism risking them to overdose, that use this drug. It is clinically imperative that we can analyse the toxicity effects of amlodipine on the morphology of the testis.

\section{Materials and Methods}

Animal
24 Adult wistar rats were obtained from the colony breed of the animal house of the Department of Anatomy, OAU, Ile-Ife. The animals were divided into three groups; two treatments and one control. In the treatment groups there were 5 rats each while the control group was assigned four rats. The rats weighed between $150 \mathrm{~g}-250 \mathrm{~g}$ with ages ranging from 10-12 weeks. They were housed in individual cages in a room with ambient temperature. The rats were fed during the experimental procedure with standard pellet diet (Sesco Feeds Ikenne, Nigeria). The weights of the rats were taken daily.

Study Group/Drug Adminstration

Amilodpine was administered orally at a dosage of $0.052 \mathrm{mg} / \mathrm{g}$ body weight and $0.104 \mathrm{mg} / \mathrm{g}$ body weight for the treated groups, once daily for 8 weeks. The control group received an equivalent volume of $0.5 \mathrm{ml}$ of normal saline.

$\mathrm{N}: \mathrm{B}$ : The actual concentration of the of the amlodipine given to each rat was obtained from calculations using the average weight of the rats per group

If a $70000 \mathrm{~g}$ adult man is given $5 \mathrm{mg}$ of amlodipine

Then a $195 \mathrm{~g}$ adult rat will receive $\frac{5 \mathrm{mg} \mathrm{X} 195}{70000 \square}=0.013 \mathrm{mg}$

$\mathrm{Nb}$ - The normal dose is $5 \mathrm{mg} / \mathrm{kg} / \mathrm{BW}$ in man

Histology

The animals were sacrificed and the scrotum of each rat opened, the testis was ligated and the whole testis was then taken out. The testis was then later fixed in $10 \%$ formal saline. After complete fixation the blocks was embedded in paraffin and sections cut at $5 \mu \mathrm{m}$ (micron) which was then stained with haematoxylin and eosin and mounted in Canada balsam. Microscopic examination of the sections was then carried out under a light microscope.

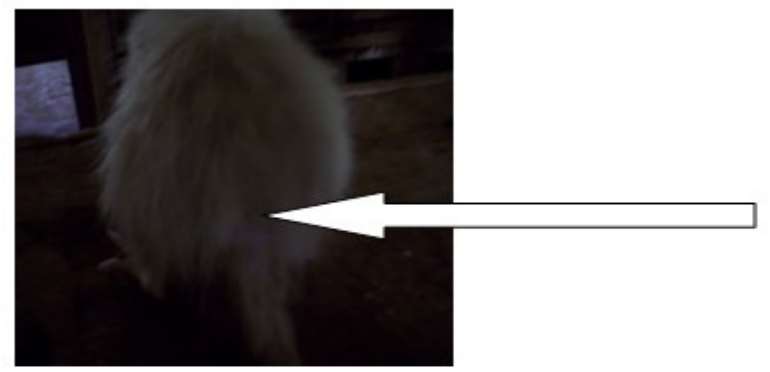

Figure 1. The thick arrow indicate loss of hair showing the toxicity effect of amilodipine on the physical appearance as when compared to the control group

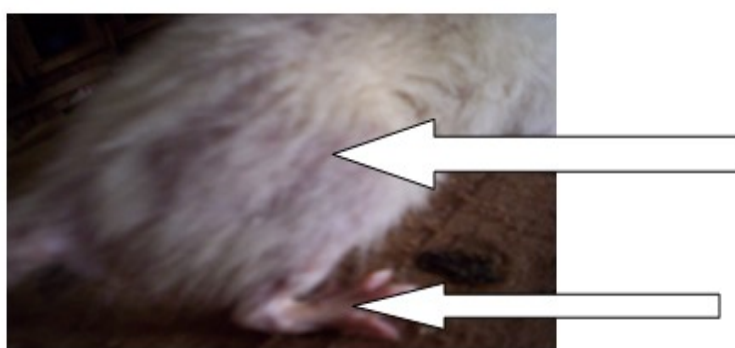

Figure 2. The thick arrows indicates loss of hair and locomotion showing the toxicity effect of amilodipine on the physical appearance as compared to the control group 


\section{Result}

\subsection{Physical Observations}

In the treatment group, hair loss observed (plate 1). Some of the treated animals also exhibited loss of locomotion and balance (2 and 3$)$. In the control group the animals remained stable and physically normal. There was neither loss of hair nor locomotion loss.

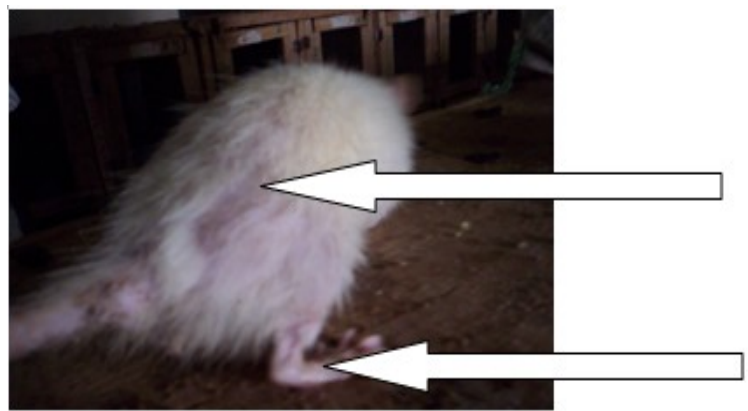

Figure 3. The thick arrows also indicates loss of hair and locomotion showing the toxicity effect of amilodipine on the physical appearance as compared to the control group

\section{Testis Histology}

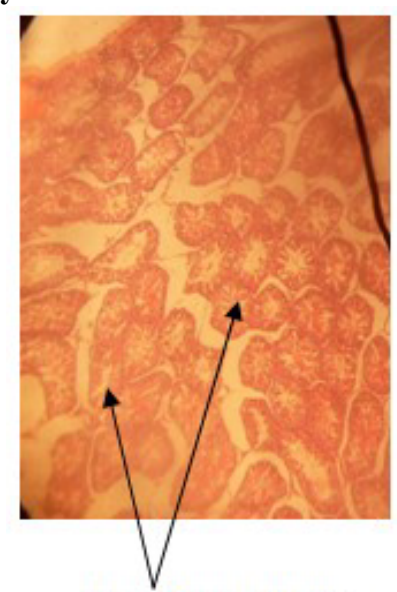

Seminiferous tubules

Figure 4. Testis histo-architecture of the rats that received normal saline (Control) showed no damage to the seminiferous tubules

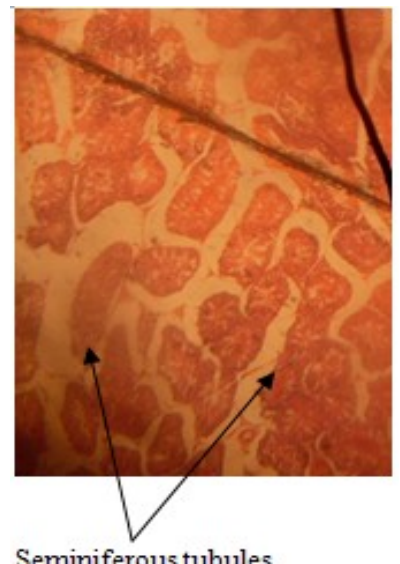

Figure 5. Testis histo-architecture of rats that received $20 \mathrm{mg} / \mathrm{kg}$ /bodyweight of Amilodipine showed progressive damage of the seminiferous tubule

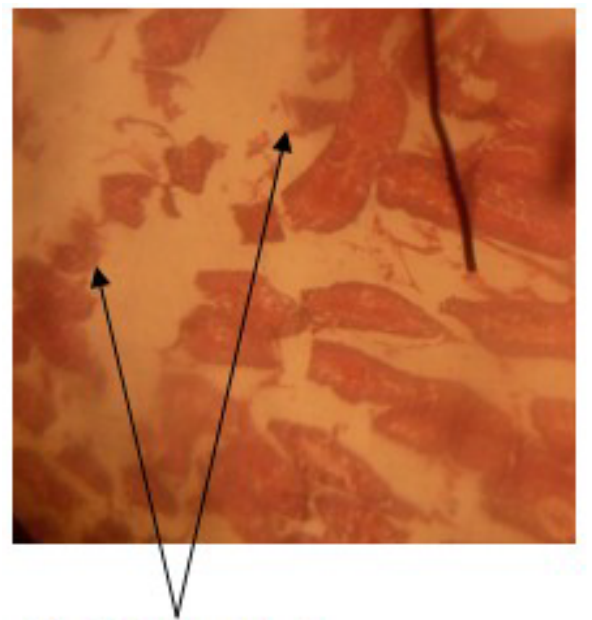

\section{Seminiferous tubules}

Figure 6. Testis histo-architecture of rats that received $40 \mathrm{mg} / \mathrm{kg} /$ bodyweight of Amilodipine showed damage to the seminiferous tubules hence scanty under the microscope

\section{Discussion}

It could be observed from the result obtained in this study that a high dose of $0.056 \mathrm{mg} / \mathrm{g} / \mathrm{bodyweight} \mathrm{of} \mathrm{amlodipine}$ gradually produced an abnormal morphology of the testis while a higher dose of $0.114 \mathrm{mg} / \mathrm{g} /$ bodyweight led to a complete destruction of the histological architecture of the testis when administered daily for 8 weeks. The high doses were designed to represent human exposure to high levels of amlodipine. This data also collaborated with physical observation.

The results showed that the drug amlodipine had a destructive effect on the seminiferous tubule in a dose related manner for the result showed a progressive destruction of the seminiferous tubules which could have also contributed to the low sperm count. Calcium channel blockers also contribute to low sperm in that calcium influx is an absolute requirement for physiological acrosome reaction in sperm both in invertebrate and mammals. Pharmacological studies suggest that the major channel in sperm head plasma membrane, modulating calcium entry and intracellular ionized calcium levels is by a L-type (a class of high voltage-activated) voltage-dependent calcium channel[26]. Calcium channel blockers also act by changing the cholesterol content of the sperm cell membrane, if you load sperm with cholesterol, you can make them nonfunctional, and that is what these calcium channel blockers are doing. It has also been suggested that antihypertensive drug can also double as a male contraceptive[27] in that long term treatment with amlodipine might be associated with significant testicular regression and reduction in serum testosterone and that dihydropridine antagonist widely used in hypertension may have some clinical implication in the management of infertility associated with hypertension. It was also discovered that calcium channel blockers had effect on the testicular weight in that calcium channel 
blockers suppress spermatogenesis[28]. Also discovered was that calcium antagonist (amlodipine) used in the treatment of hypertension $(0.04 \mathrm{mg} / \mathrm{rat} / \mathrm{day}$ for 30days $)$ decreased the plasma follicle-stimulating hormone (FSH) and testosterone but not luteinizing hormone (LH) or prolactin concentration[29].

However inasmuch as Calcium channel blocker have been reported to have adverse effect on reduction in protein synthesis, diminished incorporation of proline into new collagen and decreased hormone release in vitro, they was no significant effect in the bone mineral density at the lumbar spine (L2-L4), proximal femur and proximal and distal radius and also no effect in bone turnover, showing that calcium channel blocker used in males is not associated with either beneficial or adverse effect in bone metabolism[30]. Finally it was also observed that the drug didn't have any effect on the body weight of the animals, for the body weights of the experimental animal increased in the same fashion as that of the control.

\section{Conclusions}

It can be concluded from the result of this work that high doses of amlodipine led to abnormal morphology of the testis in male adult Wistar rats. Therefore, one can conclude that high doses of amlodipine could lead to infertility in man.

It is recommended that further work should be done to elucidate the toxicity effects of amlodipine on the testis morphology of male adult Wistar rats.

\section{REFERENCES}

[1] U.S. National Library of Medicine: Drug Information Portal - Amlodipine

[2] Kornhuber M, Trapp S, Pechmann S, Friedl A, Reichel M, Muhler C, Terfloth L, Groemer T, Spitzer G, Liedl K, Gulbins E, Tripal P, 2011. Identification of Novel Functional Inhibitors of Acid Sphingomyelinase: PLoS ONE. 6(8):e23852

[3] Romer, P. Alfred Sherwood, S. Thomas, 1977. The Vertebrate Body. Philadelphia, PA: Holt-Saunders International. pp. 385-386.

[4] E.Nieschlag, Hermann, M. Behre, H. van. Ahlen; Andrology Male Reproductive Health and Dysfunction"[2]

[5] Johnson A.D. and Gomes W.R., 1970. The testis. Academic Press, Vols 1-4.

[6] Trainer T.D., 1987. Histology of the normal testis: Am J surg Pathol (11)797

[7] Carretero O.A., S. Oparil, 2000. Essential hypertension. Part I: definition and aetiology: Circulation 101 (3): 329-35.

[8] World Health Organisation Global Health Risks 2001: Mortality and Burden Of Disease Attributable To Selected
Major Risks.Genever: World Health Organisation

[9] Lewington S, Clarke R, Qizilbash N, Peto R, Collins P, 2002. Age-Specific Relevance Of Usual Blood Pressure To Vascular Mortality: A Meta-Analysis of Individual Data For 1 million adults In 61 Prospective Studies. Lancet 360(9349):1903-13

[10] OBrien Eoin, Beevers DG, Lip Gregory YH, 2007. ABC of Hypertension. London. BMJ Books ISBN1-4051-3061-x

[11] Singer DR, Kito A, 2008. Management of Hypertension In Peripheral Arterial Disease: Does the choice of Drugs Matter? European Journal Of Vascular and Endovascular Surgery 35(6):701-8

[12] Zeng C, Villar VA, Yu P, Zhool L, Jose PA, 2009. Reactive Oxygen Species and Dopamine Receptor Function In Essential Hypertension. Clinical and Experimental Hypertension 31(2):156-78

[13] Chen X, Wen W, Anstoy KJ, Sachdev PS, 2009. Prevalence, Incidence and Risk factors Of lacunar Infarcts In a Community Sample. Neurology 73(4):266-72

[14] He FJ, Mac Gregor GA, 2009. A Comprehensive Review on Salt and Health and Current Experience of Worldwide Salt Reduction Programmes. J Hum Hypertens 23(6):363-84

[15] Vinkinson HO, Mason JM, Nicolson DJ, Campbell F, Beyer FR, Cook JV, William B, Ford GA, 2006. Lifestyle Interventions To Reduce Raised Blood Pressure: A Systemic Review Of Randomized Controlled Trials. J. Hypertens 24:215-33

[16] Haslam DW, James WP, 2005. "Obesity". Lancet 366(9492):1197-209

[17] Mesas AE, Leon-Munoz LM, Rodriguez-Artalejo F, LopezGarcia E,2011. The Effect Of Coffee On Blood Pressure and Cardiovascular Disease in Hypertensive Individually: A Systematic Review and Meta-Analysis. Am J Clin Nutr 94:113-26

[18] Vadiya A, Forman JP, 2010. Vitamin D andhypertension:Cu rrent Evidence and Future Directions : Hypertension 5(5):774-9

[19] Kearney P.M., M. Whelton, K. Reynolds, P. Muntner, P.K. Whelton, J. He, 2005. Global burden of hypertension: analysis of worldwide data: Lancet 365 (9455): 217-23.

[20] Kearney P.M., M. Whelton, K. Reynolds, P.K. Whelton, J. He, 2004. Worldwide prevalence of hypertension: A systematic review. J. Hypertens. 22 (1): 11-9.

[21] Burt V.L., P. Whelton, E.J. Roccella, 1995. Prevalence of hypertension in the US adult population. Results from the Third National Health and Nutrition Examination Survey, 1988-1991: Hypertension 25 (3): 305-13.

[22] Burt V.L., J.A. Cutler, M. Higgins, 1995. Trends in the prevalence, awareness, treatment, and control of hypertension in the adult US population. Data from the health examination surveys, 1960 to 1991:Hypertension 26 (1): 60-9.

[23] Ostchega Y., C.F. Dillon, J.P. Hughes, M. Carroll, S. Yoon, 2007. Trends in hypertension prevalence, awareness, treatment, and control in older U.S. adults: data from the National Health and Nutrition Examination Survey 1988 to 
2004: Journal of the American Geriatrics Society 55 (7): $1056-65$.

[24] Dionne JM, Abitbol CL, Flynn JT, 2012. Hypertension in infancy: Diagnosis Management and Outcome. Pediatr Nephrol. 27(1):17-32

[25] Bahl VK, Jadhau UM, Thacker HP, 2009. Management of Hypertension with the fixed Combination of Perndopril and Amilodipine in Daily Clinical practise: Results from the strong perspective, observational Multicentre Study. Am J Cardiovasc Drugs 9(3):135-42

[26] Benoff S, 1998. Voltage dependent calcium channel in mammalian spermatozoa: Front Biosci; 3:1220-40

[27] Nowak, R.J 1998. Antihypertension drug may double as male contraceptives: NIH Res; 6:27-8

[28] Rabia Latif, Ghulam Mustafa Lodhi, Muhammad Aslam, 2008. Effect of Amlodipine on Serum Testosterone, testicular weight and gonado-somatic index in adult rats: J ayyaub med coll abbottabad; 20 (4)

[29] Almaida SA, Teofilo JM, Anselmo Franci JA, Brentegani LG, Lamano-Carvalho TL (2000). Antireproductive Effect of Calcium Channel Blocker Amilodipine in Male Rats: Exp Toxicol Pathol; 52:353-6

[30] Albers MM, Johnson W, vivian V, Jackson RD (1991). Chronic use of Calcium Channel Blocker Nifedipine has no significant effect on bone metabolism in men: Bone; 12:3942 